UDC 327.7(4:479)

Submitted: 30.12 .2020

LBC 66.4(4),60

Accepted: 23.07 .2021

\title{
THE EUROPEAN UNION'S STRATEGY FOR THE SOUTH CAUCASUS COUNTRIES WITHIN THE EASTERN PARTNERSHIP PROGRAM: 20 DELIVERABLES FOR 2020
}

\author{
Elena F. Parubochaya \\ Volgograd State University, Volgograd, Russian Federation \\ Anna S. Prygunkova \\ Volgograd State University, Volgograd, Russian Federation
}

\begin{abstract}
Introduction. Due to the destabilization of the situation in the countries of the South Caucasus in 2020 , the region is of particular relevance today. At the present stage, it is an object of geopolitical competition for numerous international actors: the Russian Federation, the United States of America, the European Union, the Republic of Turkey. The article examines the EU policy in the process of implementing the Eastern Partnership program as part of the European political strategy. In relation to the South Caucasus region, the interim results of the EU's activities on the implementation of 20 deliverables for 2020 in relation to the states of the South Caucasus are analyzed. Methods. Comparative analysis makes it possible to give a comprehensive assessment of European policy in the region by identifying priority areas and development prospects by comparing the intermediate results of 20 deliverables for 2020 in the South Caucasus countries within the framework of their bilateral relations with the EU. Analysis. The analysis of the activities of the European Union in relation to the South Caucasus countries is associated with the determination of the prospects for the development of the European strategy in the region. The analysis included tracking the dynamics of the implementation of the 20 deliverables for 2020 in relation to Azerbaijan, Armenia and Georgia, as well as options for developing a European strategy in the South Caucasus countries, taking into account the new policy in the context of the Eastern Partnership beyond 2020. Results. As a result of the analysis, the EU's competitive advantages in the South Caucasus were determined by identifying areas in which the EU's geopolitical interests intersect with other actors.

Key words: European Union, Eastern Partnership, 20 deliverables for 2020, South Caucasus, EU foreign policy.

Citation. Parubochaya E.F., Prygunkova A.S. The European Union's Strategy for the South Caucasus Countries Within the Eastern Partnership Program: 20 Deliverables for 2020. Vestnik Volgogradskogo gosudarstvennogo universiteta. Seriya 4. Istoriya. Regionovedenie. Mezhdunarodnye otnosheniya [Science Journal of Volgograd State University. History. Area Studies. International Relations], 2021, vol. 26, no. 4, pp. 183-192. (in Russian). DOI: https://doi.org/10.15688/jvolsu4.2021.4.16
\end{abstract}

\section{СТРАТЕГИЯ ЕВРОПЕЙСКОГО СОЮЗА В ОТНОШЕНИИ СТРАН ЮЖНОГО КАВКАЗА В РАМКАХ ПРОГРАММЫ ВОСТОЧНОГО ПАРТНЕРСТВА: 20 РЕЗУЛЬТАТОВ К 2020 ГОДУ \\ Елена Федоровна Парубочая}

Волгоградский государственный университет, г. Волгоград, Российская Федерация

Анна Сергеевна Прыгункова

Волгоградский государственный университет, г. Волгоград, Российская Федерация 
Аннотация. Введение. В связи с дестабилизацией ситуации в странах Южного Кавказа в 2020 г., данный регион сегодня имеет особую актуальность. На современном этапе он является объектом геополитической конкуренции для многих международных акторов: Российской Федерации (далее - РФ), Соединенных Штатов Америки (далее - США), Европейского союза (далее - ЕС), Турецкой Республики (далее - ТР). В статье рассматривается политика ЕС в процессе реализации программы Восточного партнерства (далее - ВП) как части европейской политической стратегии. В отношении Южно-Кавказского региона анализируются промежуточные итоги деятельности ЕС по реализации 20 результатов к 2020 г. в отношении государств Южного Кавказа. Meтодbl. Сравнительный анализ позволит дать комплексную оценку европейской политике в регионе за счет выявления приоритетных областей и перспектив развития путем сравнения промежуточных итогов 20 результатов к 2020 г. в странах Южного Кавказа в рамках их двусторонних отношений с ЕС. Aнализ. Анализ деятельности Европейского союза в отношении стран Южного Кавказа связан с определением перспектив развития европейской стратегии в регионе. Анализ включал прослеживание динамики реализации программы 20 результатов к 2020 г. в отношении Азербайджана, Армении и Грузии, а также варианты развития европейской стратегии в странах Южного Кавказа с учетом новой политики в контексте программы «Восточное партнерство после 2020». Результаты. В результате анализа была дана комплексная оценка политике ЕС на Южном Кавказе за счет выявления приоритетных сфер в реализации 20 результатов к 2020 г. в рамках двусторонних отношений ЕС с Арменией, Азербайджаном и Грузией. Вклад авторов. В данной статье Е.Ф. Парубочей были определены характерные особенности реализации европейской стратегии в регионе, а также выявлены предпосылки ее формирования. А.С. Прыгунковой были определены промежуточные итоги программы ВП в каждой из стран Южного Кавказа в контексте реализации 20 результатов к 2020 году.

Ключевые слова: Европейский союз, Восточное партнерство, 20 результатов к 2020 г., Южный Кавказ, внешняя политика ЕС.

Цитирование. Парубочая Е. Ф., Прыгункова А. С. Стратегия Европейского союза в отношении стран Южного Кавказа в рамках программы Восточного партнерства: 20 результатов к 2020 году // Вестник Волгоградского государственного университета. Серия 4, История. Регионоведение. Международные отношения. 2021. - T. 26, № 4. - C. 183-192. - DOI: https://doi.org/10.15688/jvolsu4.2021.4.16

Введение. Первоначально Сообщение Европейской комиссии Совету и Европейскому парламенту по политике расширения Европы не включало в себя Азербайджан, Армению и Грузию. В обновленной Европейской политике соседства (далее - ЕПС) страны Южного Кавказа являются одним из приоритетных направлений внешней политики ЕС [13]. В настоящее время они привлекают пристальное внимание международных акторов, не в последнюю очередь исходя из соображений европейской безопасности.

Теме европейской стратегии в регионе Южного Кавказа в рамках ЕПС и программы ВП посвящены многочисленные исследования. Среди отечественных исследователей, изучающих сотрудничество ЕС с Азербайджаном, Арменией и Грузией на современном этапе, можно особенно выделить работы И.М. Узнародова, Ю.С. Кудряшовой, А.А. Языковой, И.В. Болговой. Эволюцию политики ЕС в контексте взаимодействия с Южным Кавказом в своих трудах исследовали К.В. Юматов, А. Айвазян [8].

Отдельная группа исследователей фокусировала внимание на месте и роли стран
Южного Кавказа в региональной геополитической системе, а также в системе региональной безопасности. К таким авторам относится С.М. Иванов, Н.Г. Галоян и Г.С. Котанджян. Механизмы реализации Европейской политики соседства на примере Азербайджана, Армении и Грузии исследовал А.А. Стрелков. Различные аспекты участия государств Южного Кавказа в программе Восточного партнерства исследуют П.А. Барахвостов, К.И. Елизарьева [2].

Среди работ зарубежных ученых этапам и проблемам формирования ЕПС посвящены труды С. Ганзле, Б. Липперта, С. Мюллер-Краеннер. Т.С. Герман и П. Семнеби фокусировали свое внимание на участии ЕС в актуальных событиях, происходящих на Южном Кавказе [20]. Особенностям двусторонних взаимоотношений ЕС со странами Южного Кавказа посвящены публикации М. Йирачека, Л. Алиевой и А. Читаладзе [12].

В рамках данной работы представляется важным дать комплексную оценку политике ЕС в странах Южного Кавказа в контексте реализации 20 результатов до 2020 г., ут- 
вержденных в рамках программы Восточного партнерства в 2017 году. Для достижения поставленной цели необходимо, во-первых, выявить предпосылки запуска 20 результатов до 2020 года. Во-вторых, определить особенности и динамику реализации программы в отношении к Азербайджану, Армении и Грузии. В-третьих, спрогнозировать возможные варианты развития европейской стратегии в странах Южного Кавказа, с учетом новой утвержденной политики относительно программы «Восточное партнерство после 2020 г.».

Реализация европейской стратегии по отношению к странам Южного Кавказа рассматривается через теорию регионализма, позволяющую охарактеризовать всестороннее взаимодействие акторов европейского региона с государствами Южного Кавказа, а также обосновать доминирующую роль ЕС в сотрудничестве с ними.

Методы исследования. Методологической основой исследования выступает сравнительный анализ. Использование метода сравнения позволило сопоставить результаты реализации программы ВП в отношении Азербайджана, Армении и Грузии. Эмпирической базой исследования послужили:

- нормативно-правовые акты ЕС (20032020 гг.);

- статистические данные (2017-2020 гг.);

- заявления высших должностных лиц EC (2017-2020 гг.).

Анализ. Сама мысль о формировании европейской стратегии по отношению к странам Южного Кавказа зародилась среди политических кругов ЕС после распада СССР. Большое значение в формировании подхода ЕС по отношению к Южному Кавказу имели этнические противоречия, которые обострились в регионе в рамках нагорно-карабахского конфликта. Интерес к его мирному урегулированию особенно проявляла Франция, так как в этой стране присутствуют многочисленные представители армянской и грузинской диаспор. Определенную роль в его разрешении играли Италия, Швеция и Финляндия в рамках Минской группы ОБСЕ.

В качестве последствий распада СССР Армения, Грузия и Азербайджан получили не только независимость и суверенитет, но и серьезный экономический кризис. Это стало поводом для сохранения и продолжения активной европейской политики в регионе.

В то же время у стран Южного Кавказа не было сторонника и лоббиста в ЕС. В связи с этим Армения, Грузия и Азербайджан были включены в ЕПС относительно поздно, в июне 2004 года.

Основным фактором привлечения внимания ЕС, а также международного сообщества, являются природные ресурсы региона, а именно газ и нефть, в основном добываемые с территории Азербайджана. ЕС в значительной степени зависит от поставок энергоресурсов из очень ограниченного числа стран. В этой области Азербайджан занял лидирующее место с ростом ВВП примерно на $20 \%$ с 1995 г., достигнув пика в 2006-2008 гг. благодаря своим запасам нефти, и мог получить экономическую независимость [11]. В результате этого ЕС осознал необходимость всерьез заняться проблемой диверсификации природных ресурсов, и Южный Кавказ превратился в транзитный маршрут, приносящий энергетические запасы в Европу.

С целью усиления своего влияния в регионе ЕС в рамках ЕПС начал разрабатывать инициативы для более тесного регионального сотрудничества. Государства Южного Кавказа совместно с еще тремя постсоветскими странами (Беларусь, Молдова, Украина) в 2009 г. стали участниками программы ЕС Восточное партнерство, одной из трех масштабных программ ЕС, направленных на сближение с соседними регионами.

Для более детального исследования стратегии ЕС на Южном Кавказе в рамках программы Восточного партнерства рациональнее разделить процесс ее реализации на три этапа: 1) 2009-2013 гг.; 2) 2013-2017 гг.; 3) 2017-2020 гг.

За первые четыре года реализации ВП, ЕС столкнулся с множеством проблем, связанных с особенностями моделей развития каждой из стран Южного Кавказа. Процесс преобразования региона с акцентом на европейские стандарты невозможно было продолжать по единому шаблону. В связи с экономическими, демографическими и политическими факторами Армения, Азербайджан и Грузия имели абсолютно разные показатели в скорости развития, чего ЕС изначально не учел [2, с. 203]. 


\section{МЕЖДУНАРОДНЫЕ ОТНОШЕНИЯ В ПРОШЛОМ И НАСТОЯЩЕМ}

В рамках первого этапа наиболее активные преобразования произошли в Грузии. Революция, случившаяся в 2004 г., окончательно сформировала «европейский» вектор во внешней политике страны. ВВП Грузии вырос с 11,07 млрд долл. США в 2009 г. до 17,19 млрд долл. США в 2013 г. [4]. Основные реформы правительства были направлены на либерализацию экономики и модернизацию страны по европейским стандартам.

В Армении скорость экономических трансформаций была ограничена в связи с особенностями модели экономического развития страны, которой Армения была вынуждена придерживаться из-за дефицита природных ресурсов и зависимости от других государств, в том числе и от России. Несмотря на это, за первые четыре года участия в ВП Армения смогла увеличить свой ВВП с 8,65 млрд долл. США в 2009 г. до 11,12 млрд долл. США в 2013 г. [1]. Постепенно формировалась и нормативно-правовая база сотрудничества с ЕС в рамках ВП, которая должна была способствовать ускорению темпов «европеизации» государства.

Азербайджан, в отличие от Грузии и Армении, оставался единственной страной Южного Кавказа, которая сохраняла как экономическую, так и политическую дистанцию в контексте реформистских идей ЕС. Во многом это обусловлено самостоятельной экономической политикой Азербайджана, чей ВВП уже на 2009 г. составил 12,2 млрд долл. США [11], а к 2013 достиг 16,2 млрд долл. США [3]. Именно экономические ресурсы данного участника ВП послужили поводом для подписания с ЕС декларации по газопроводу «Южный коридор». Азербайджан, таким образом, к завершению первого этапа реализации ВП стал главным торговым партнером ЕС при товарообороте 16,7 млрд евро, 14,37 млрд евро из которых приходились на импорт нефтепродуктов в ЕС [17].

Второй этап реализации ВП был посвящен работе над ошибками, допущенными в результате применения ЕС общего подхода по отношению ко всем странам Южного Кавказа. Таким образом, с 2014 по 2017 г. в отношении с Грузией начинается взаимодействие с акцентом на вектор сотрудничества, установленный в Соглашении об ассоциации: раз- витие экономики, реформы законодательной базы и судебной системы [6].

Взаимодействие с Арменией стало более регламентированным в рамках ВП. Основным вектором сотрудничества в данном случае представители ЕС обозначили демократизацию страны по европейским стандартам: развитие и защита прав и свобод человека, распространение и приверженность демократическим ценностям, верховенство закона [21].

Политический вектор, реализуемый ЕС по отношению к Азербайджану, включал в себя начало стратегической модернизации страны. Сохраняя тесные экономические связи, правящие элиты ЕС стали все больше делать акцент на политическом диалоге с официальными представителями Азербайджана. В результате осенью 2016 г. Совет ЕС утвердил мандат Европейской комиссии по вопросу переговоров о заключении всеобъемлющего соглашения ЕС с Азербайджаном, которое должно было заменить аналогичный документ 1996 года.

В ноябре 2017 г. представители государств-членов ЕС встретились в Брюсселе с главами государств-членов ВП. По итогам саммита стороны согласовали совместную декларацию, которая подтверждала смещение национальных политик стран ВП в сторону европейского вектора. В декларации подчеркивалось, что ЕС и его шесть восточных партнеров одобрили совместный план работы 20 результатов к 2020 г., который стал основным фокусом в процессе реализации ВП, направленным на стратегическое информировании граждан об эффективности европейской политики [22].

Таким образом, предложенные Европейской комиссией 20 результатов на 2020 г. были направлены на достижение конкретных целей и активизацию действий в четырех ключевых приоритетных областях: экономическое развитие; укрепление институтов государственного управления; связь и энергоснабжение; мобильность и контакты между людьми. Кроме того, выделялось несколько смежных целей, среди которых более активное взаимодействие с организациями гражданского общества, вопрос гендерного равенства, усиление стратегических коммуникаций и поддержка разнообразных и независимых СМИ [9]. 
Для достижения поставленных целей такого масштабного плана ЕС использовались различные инструменты поддержки странпартнеров. В частности, стоит выделить такие программы, как EU4Business и EU4Youth Programme, в рамках которых осуществлялся масштабный комплекс действий, нацеленный на всестороннюю поддержку восточных соседей ЕС в процессе реализации 20 результатов к 2020 году.

Инициатива EU4Business обобщает европейские программы поддержки предпринимательства и предлагает новые возможности для государств-партнеров. Одной из наиболее актуальных тем для проектов в рамках EU4Business является упрощение доступа к европейским рынкам малому и среднему бизнесу стран ВП. По итогам успешной реализации EU4Business с 2009 по 2017 г. в рамках 20 результатов к 2020 г. государства Южного Кавказа стали участниками ряда новых экономических проектов. В частности, весной 2020 г. стартовала программа «Цифровая трансформация армянских МСП».

EU4Youth - программа EC, реализуемая в период 2017-2020 гг. и содействующая активному участию молодежи из стран ВП в жизни общества и расширению возможностей для их трудоустройства. За три года реализации бюджет программы составил 22,75 млн евро. Эффективность EU4Youth подтвердилась одобрением Европейской комиссией в конце 2020 г. третьего модуля программы в течение 2021 г. и утверждением дополнительного бюджета в 16 млн евро [24].

В контексте развития гражданского общества как одной из приоритетных сфер в рамках 20 результатов к 2020 г. ЕС привлекал организации гражданского общества и муниципальные органы власти к мониторингу результатов программ поддержки. Таким образом, анализ промежуточных итогов 20 результатов к 2020 г. осуществлялся как в рамках совместной работы ЕС с партнерами, так и индивидуально каждым актором, в том числе и государствами Южного Кавказа.

В июле 2020 г. Институт политики Грузии опубликовал отчет «Реализация Грузией 20 результатов Восточного партнерства к 2020 г.» [19]. В обзоре отражен прогресс и проблемы, возникшие при решении тех или иных задач. За отчетный период было усовершенствовано антидискриминационное законодательство. Стамбульские конвенции ратифицированы, и сейчас грузинское законодательство почти полностью соответствует международным стандартам. Активизировалось участие женщин в бизнесе и программе EU4Youth.

С целью укрепления потенциала организаций гражданского общества Грузии в рамках 20 результатов к 2020 г. ЕС остается крупнейшим финансовым донором. В рамках Единого механизма поддержки ЕС финансовая помощь, выделенная на развитие гражданского общества Грузии, составила $18,55-$ 22,65 млн евро (2017-2020 гг.).

Грузия пытается в полной мере использовать возможности интеграции своей экономики с ЕС через Соглашение о глубокой и всеобъемлющей зоне свободной торговли. По итогам на 2020 г. ЕС является главным торговым партнером Грузии, на долю которого приходится около 27 \% ее общего товарооборота [5]. Несмотря на это, есть проблемы со свободным доступом малого и среднего бизнеса к европейским рынкам.

Согласно Программе регионального развития на 2018-2021 гг. только 42,3 \% занятого населения нанимается работодателем: 84,5 \% находится в Тбилиси, а 45,6 \% - в Аджарии [25]. Во всех остальных регионах количество занятых ниже, чем в среднем по стране, и есть резкие различия между регионами с точки зрения экономического и социального развития. Не произошло заметных изменений в законодательстве и политике в области финансирования партийных кампаний. Ключевым негативным фактором является отсутствие автономного подразделения, отвечающего за расследование коррупционных дел.

Грузия значительно отстает и в процессе сближения с ЕС в области экологического руководства. Недостаточное финансирование, выделение лишь 0,4 \% государственного бюджета на охрану окружающей среды (около 60 млн лари) в сочетании с дефицитом кадровых ресурсов привели к значительным задержкам и проблемам в реализации Третьего государственного плана действий по охране окружающей среды (NEAP) [23].

Открытие первой и на сегодняшний период единственной Европейской школы ВП в 


\section{МЕЖДУНАРОДНЫЕ ОТНОШЕНИЯ В ПРОШЛОМ И НАСТОЯЩЕМ}

Тбилиси является позитивным сигналом от ЕС. Однако количество доступных в настоящее время стипендий довольно ограничено как в рамках школы, так и в целом в области академической мобильности.

Сотрудничество ЕС с Арменией в период реализации 20 результатов к 2020 г. проходило также в рамках Соглашения о всеобъемлющем и расширенном партнерстве между Республикой Армения и ЕС, подписанном осенью 2017 г. [14]. В сфере сквозных результатов Армения, как и Грузия, обновила и частично реализовала план действий по гендерным вопросам. В рамках двухлетнего проекта EU4Youth «Лучшие навыки для лучшего будущего» с участием Армении более 1300 тыс. молодых людей прошли обучение в области предпринимательства, а также было пересмотрено 12 молодежных политик.

Активно проводилась просветительская деятельность ЕС в Армении в 2019 г. в честь празднования 10-летия ВП, тем самым обеспечивая усиление стратегической коммуникации и поддержку независимых медиа и СМИ.

В 2019 г. на долю ЕС приходилось около $20 \%$ от общего товарооборота Армении, что сделало его вторым экономическим партнером Армении после Российской Федерации. Объем торговли между всеми странами ВП и ЕС с Арменией увеличился в период с 2016 по 2019 г. на 27 \% [9]. Для Армении был подготовлен комплекс мероприятий в контексте развития умной специализации - политики, основанной на акценте на сильные стороны и конкурентные преимущества каждого регионального актора. На реализацию проектов в сферах, утвержденных в 20 результатах к 2020 г., ЕС для Армении было выделено более 200 млн евро [14].

С целью улучшения работы институтов государственного управления Армения приняла новые всеобъемлющие реформы сектора правосудия. После принятых изменений ЕС положительно оценил выборы 2018 г. в Армении и даже поспособствовал их организации. «К вашему сведению, весь объем помощи изза рубежа будет исключительно европейским, то есть ЕС и три государства-члена окажут содействие. Не будет ни американских денег, ни японских денег», - заявил посол ЕС в Армении П. Свитальский [7].
Инициатива ЕС и Международных финансовых институтов по развитию энергетической эффективности повысила политическую заинтересованность в Армении. Прогресс в области защиты окружающей среды в отношении Армении оценивается как «умеренный». В январе 2020 г. при поддержке ЕС открылась Лаборатория ГНКО «Центр мониторинга окружающей среды и информации» в г. Ереване.

В июле 2018 г. Европейский парламент принял резолюцию о переговорах по новому двустороннему соглашению, в которой подчеркивалось, что углубление отношений зависит от соблюдения Азербайджаном основных ценностей и принципов демократии, верховенства закона, надлежащего управления и уважения к человеческим правам и основным свободам [16]. Однако на начало 2020 г. правительство Азербайджана так и не выразило приверженности к подписанию данного документа. В отличие от Грузии или Армении, Азербайджан выстраивает самостоятельный внешнеполитический вектор, основываясь на своих государственных интересах. Это объясняет весьма ограниченный прогресс в области сквозных результатов.

Несмотря на это, Азербайджан занимает 146-е место из 167 стран в рейтинге демократии Economist Intelligence Unit за 2019 г. [15] и классифицируется как «несвободный» в отчете «Свобода в мире» за 2020 г. [10]. Несмотря на надежды, что парламентские выборы в феврале 2020 г. могли бы привести к увеличению свободы оппозиции, последствия выборов характеризовались усилением репрессий в отношении политической оппозиции, журналистов и правозащитников.

Наиболее прогрессивной в рамках 20 результатов к 2020 г. в отношении Азербайджана стала экономическая сфера. На 2019 г. ЕС оставался ключевым торговым партнером Азербайджана, на которого приходилось около $37 \%$ от общей торговли страны [17]. ЕС оказал помощь 9198 компаниям Азербайджана в финансировании, обучении и поддержке выхода экспорта на новые рынки в рамках инициативы EU4Business, что способствовало созданию более 36267 новых рабочих мест [18]. В 2019 г. в рамках 20 результатов к 2020 г. Азербайджан также присоединился к 
Фонду Е5Р, который развивает экологическое партнерство и энергетическую эффективность в Восточной Европе.

Результаты. Таким образом, прогресс, достигнутый в реализации 20 результатов к 2020 г. в странах Южного Кавказа, в ежегодных мониторингах ЕС был оценен как «умеренный». Несмотря на ощутимое развитие, общая картина по-прежнему дает довольно неоднозначные результаты. Из 20 результатов к 2020 г. достигнуто 5 \% целей, значительного прогресса удалось достигнуть по $70 \%$ задач и $25 \%$ планов так и не реализовались. Несмотря на это, в рамках он-лайн-саммита ВП летом 2020 г. европейские лидеры положительно оценили достигнутые результаты в период за последние три года. Однако для более эффективной реализации программы после 2020 г. ЕС призывает своих партнеров активизировать усилия для достижения дополнительного прогресса во всех областях, включая нерешенные проблемы в области правосудия и борьбы с коррупцией, а также в отношении гендерного равенства и защиты окружающей среды.

Вероятно, что новый пакет результатов будет утвержден в рамках полноценного саммита ВП в 2021 году. При условии его утверждения в отношении государств Южного Кавказа, в частности после 2020 г., ожидается усиление экономического влияния ЕС в Грузии и Армении при реализации более сдержанной экономической стратегии в отношении Азербайджана. Одновременно с этим в рамках двусторонних отношений ЕС с Азербайджаном предвидится смещение вектора на экологический аспект сотрудничества. Наконец, во всех трех государствах Южного Кавказа планируется реализация цифровой трансформации, что впоследствии может обеспечить ЕС значительное преимущество в борьбе за стратегическое влияние на данной территории.

В период пандемии COVID-19 в 2020 г. EC оказывал всестороннюю поддержку своим партнерам на Южном Кавказе. На основе сравнительного анализа двусторонних отношений ЕС со странами Южного Кавказа в контексте реализации 20 результатов к 2020 г. была дана комплексная оценка приоритетам европейской политики в регионе. Исходя из этого, ЕС намерен наращивать сотрудниче- ство с Арменией, продолжать активный диалог с Грузией и сохранять партнерские отношения с Азербайджаном.

\section{СПИСОК ЛИТЕРАТУРЫ}

1. Армения - Валовый Внутренний Продукт. - Электрон. текстовые дан. - Режим доступа: https://datacommons.org/place/country/ARM?utm medium $=$ explore $\& \mathrm{mprop}=$ amount\&popt $=$ EconomicActivity\&cpv=activitySource\%2CGross DomesticProduction\&hl=ru (дата обращения: 20.03.2021). - Загл. с экрана.

2. Барахвостов, П. А. Кавказское измерение «Восточного партнерства» (2009-2016) / П. А. Барахвостов // Вестник МГИМО Университета. 2016. - № 4. - С. 199-208.

3. ВВП Азербайджана 1990-2019. - Электрон. текстовые дан. - Режим доступа: https://be5.biz/ makroekonomika/gdp/az.html (дата обращения: 20.03.2021). - Загл. с экрана.

4. Грузия - Валовый Внутренний Продукт. Электрон. текстовые дан. - Режим доступа: https:/ /knoema.ru/atlas/\%D0\%93\%D1\%80\%D1\% 83\%D0\% $\mathrm{B} 7 \% \mathrm{D} 0 \% \mathrm{~B} 8 \% \mathrm{D} 1 \% 8 \mathrm{~F} / \% \mathrm{D} 0 \% 92 \% \mathrm{D} 0 \% 92 \% \mathrm{D} 0 \% 9 \mathrm{~F}$ (дата обращения: 20.03.2021). - Загл. с экрана.

5. Отношения ЕС - Грузия в фактах и цифpax. - 2020. - Электрон. текстовые дан. - Режим доступа: https://www.euneighbours.eu/ru/vostok/ stay-informed/publications/otnosheniya-es-gruziya(дата обращения: 23.03.2021). - Загл. с экрана.

6. Соглашение о партнерстве и сотрудничестве между ЕС и Грузией 1996 г. // Сайт Московской государственной юридической академии. - Электрон. текстовые дан. - Режим доступа: http://eulaw. edu.ru/documents/legislation/eea/pca georgia.htm (дата обращения: 01.02.2021). - Загл. с экрана.

7. Халатян, А. «Накануне схватки»: Как Евросоюз влияет на выборы в Армении / А. Халатян // Евразия Эксперт. - 2018. - Электрон. текстовые дан. Режим доступа: https://eurasia.expert/nakanuneskhvatki-kak-evrosoyuz-vliyaet-na-vybory-v-armenii/ (дата обращения: 03.02.2021). - Загл. с экрана.

8. Юматов, Ю. К. Эволюция политики Европейского союза на Южном Кавказе / Ю. К. Юматов // Вестник Томского государственного университета. - 2012. - № 1 (17). - С. 126-131.

9. 20 Deliverables For 2020 Monitoring - State of Play in February 2020. - 2020. - Electronic text data. Mode of access: https://www.euneighbours.eu/sites/ default/files/publications/2020-06/Monitoring\% 20Spring\%202020 20\%20Deliverables\%20for $\% 202020$.pdf (date of access: 11.02.2021). - Title from screen.

10. 2020 Freedom in the World report. - 2021.Electronic text data. - Mode of access: https:// 
freedomhouse.org/explore-the-map?type= fiw\&year=2021 (date of access: 11.02.2021). - Title from screen.

11. Azerbaijan GDP - real growth rate. -2020 . Electronic text data. - Mode of access: http:// www.indexmundi.com/azerbaijan/gdp_real_growth_ rate.html (date of access: 11.02.2021).-Title from screen.

12. Chitaladze, A. Understanding Europeanization in Georgia and Armenia - Discourses, Perceptions and the Impact on Bilateral Relations / A. Chitaladze // Analytical Bulletin. - 2015. - № 8. - P. 29-54.

13. Communication from the Commission to the Council and the European Parliament // Commission of the European Communities. - 2003. - Electronic text data. - Mode of access: https://eeas.europa.eu/ archives/docs/enp/pdf/pdf/com03_104_en.pdf (date of access: 14.03.2021). - Title from screen.

14. Comprehensive and Enhanced Partnership Agreement between the European Union and the European Atomic Energy Community and their Member States, of the one part, and the Republic of Armenia, of the other part. - 2017. - Electronic text data. - Mode of access: https://www.consilium. europa.eu/en/documents-publications/treatiesagreements/agreement/?id=2017024\& DocLanguage $=$ en (date of access: 11.02.2021). - Title from screen.

15. Democracy Index 2019 // Economist Intelligence Unit. - 2020. - Electronic text data. - Mode of access: https://www.eiu.com/topic/democracyindex/ (date of access: 04.03.2021). - Title from screen.

16. European Parliament recommendation of 4 July 2018 to the Council, the Commission and the VicePresident of the Commission // High Representative of the Union for Foreign Affairs and Security Policy on the negotiations on the EU-Azerbaijan Comprehensive Agreement. - 2018. - Electronic text data. - Mode of access: https://www. europarl.europa. eu/doceo/document/TA-8-2018-0294_EN.html (date of access: 04.03.2021). - Title from screen.

17. European Union, Trade in goods with Azerbaijan. - 2021. - Electronic text data. - Mode of access: https://webgate.ec.europa.eu/isdb_results/ factsheets/country/details_azerbaijan_en.pdf(date of access: 14.04.2021). - Title from screen.

18. Facts and Figures about EU-Azerbaijan Relations. - 2020. - Electronic text data. - Mode of access: https://ec.europa.eu/neighbourhoodenlargement/sites/near/files/eap_factsheet azerbaijan.pdf(date of access: 03.04.2021). - Title from screen.

19. Georgias Implementation of 20 Eastern Partnership Deliverables for 2020. - 2020. - Electronic text data. - Mode of access: http://gip.ge/georgiasimplementation-of-20-eastern-partnershipdeliverables-for-2020/ (date of access: 03.04.2021).Title from screen.
20. German, T. C. Corridor of Power: The Caucasus and Energy Security / T. C. German // Caucasian Review of International Affairs. - 2008. - № 2 - P. 64-65.

21. Implementation of the European Neighbourhood Policy in Armenia. Progress in 2014 and recommendations for actions: Joint Communication to the European Parliament, the Council, the European Economic and Social Committee and the Committee of the Regions. EC Doc. SWD (2015) 63 final. - Brussels, 2015. - Electronic text data. - Mode of access: https://eeas.europa.eu/archives/docs/enp/ pdf/2015/armenia-enp-report-2015_en.pdf (date of access: 03.04.2021). - Title from screen.

22. Joint Declaration of the Eastern Partnership Summit. - 2017. - Electronic text data. - Mode of access: https://data.consilium.europa.eu/doc/ document/ST-14821-2017-INIT/en/pdf(date of access: 12.04.2021). - Title from screen.

23. Ministry of Finance, Georgia. State Budget. 2020. - Electronic text data. - Mode of access: https:// mof.ge/5261 (date of access: 12.04.2021). - Title from screen.

24. Newsletter of theEU4Youth Programme. -2020. Electronic text data. - Mode of access: https:// www.euneighbours.eu/sites/default/files/ publications/2020-12/EU4Youth_Newsletter December_2020.pdf(date of access: 03.04.2021). - Title from screen.

25. Regional Development Program of Georgia for 2018-2021 Years // Ministry of Regional Development and Infrastructure of Georgia. - 2021. - Electronic text data. - Mode of access: http://extwprlegs1.fao.org/ docs/pdf/geo185566ENG.pdf (date of access: 07.04.2021). - Title from screen.

\section{REFERENCES}

1. Armeniya - Valoviy Vnutrenniy Product [Armenia - Gross Domestic Product]. URL: https:// datacommons.org/place/country/ARM?utm_medium $=$ explore\&mprop =amount\&popt $=$ Economic Activity\&cpv=activitySource\%2CGross Domestic Production\&hl=ru (accessed 20 March 2021).

2. Barakhvostov P.A. Kavkazskoe izmeremie «Vostochnogo partnerstva» (2009-2016) [The Caucasian Dimension of the Eastern Partnership in 2009-2016]. Vestnik MGIMO Universiteta [MGIMO Review of International Relations], 2016, no. 4, pp. 199-208.

3. VVP Azerbaidjana 1990-2019 [GDP of Azerbaijan 1990-2019]. URL: https://be5.biz/ makroekonomika/gdp/az.html (accessed 20 March 2021).

4. Gruziya - Valoviy Vnutrenniy Product [Georgia - Gross Domestic Product]. URL: https:// knoema.ru/atlas/\%D0\%93\%D1\%80\%D1\%83\%D0\% 
B7\%D0\%B8\%D1\%8F/\%D0\%92\%D0\%92\%D0\%9F (accessed 20 March 2021).

5. Otnosheniya ES - Gruziya v faktakh $i$ tsifrakh [Facts and Figures About EU-Georgia Relations], 2020. URL: https://www.euneighbours.eu/ $\mathrm{ru} /$ vostok/stay-informed/publications/otnosheniyaes-gruziya- (accessed 23 March 2021).

6. Soglasheniye o partnerstve i sotrudnichestve mezhdu ES i Gruziyey 1996 g. [EU-Georgia Partnership and Cooperation Agreement 1996]. Sayt Moskovskoy gosudarstvennoy yuridicheskoy akademii [Website of the Moscow State Law Academy]. URL: http:// eulaw.edu.ru/documents/legislation/eea/pca georgia.htm (accessed 01 February 2021).

7. Khalatyan A. «Nakanune skhvatki»: Kak Yevrosoyuz vliyayet na vybory v Armenii ["On the Eve of the Fight": How the European Union Affects the Elections in Armenia]. Evraziya Ekspert, 2018. URL: https://eurasia.expert/nakanune-skhvatki-kakevrosoyuz-vliyaet-na-vybory-v-armenii (accessed 03 February 2021).

8. Yumatov Y.K. Evolyutsiya politiki Yevropeyskogo soyuza na Yuzhnom Kavkaze [Evolution of European Union Policy in the South Caucasus]. Vestnik Tomskogo gosudarstvennogo universiteta [Tomsk State University Journal], 2012, no. 1 (17), pp. 126-131.

9. 20 Deliverables For 2020 Monitoring - State of Play in February 2020, 2020. URL: https:// www.euneighbours.eu/sites/default/files/ publications/2020-06/Monitoring\% 20Spring\% 202020_20\%20Deliverables\%20for\%202020.pdf (accessed 11 February 2021).

10. 2020 Freedom in the World Report, 2021. URL: h t tps://freed om house.org/explore-themap?type=fiw\&year=2021 (accessed 11 February 2021).

11. Azerbaijan GDP - Real Growth Rate, 2020. URL: http:/www.indexmundi.com/azerbaijan/gdp real_growth_rate.html (accessed 11 February 2021).

12. Chitaladze A. Understanding Europeanization in Georgia and Armenia. Analytical Bulletin, 2015, no. 8 , pp. 29-54.

13. Communication from the Commission to the Council and the European Parliament. Commission of the European Communities, 2003. URL: https:// eeas.europa.eu/archives/docs/en p/pdf/pdf/ com03_104_en.pdf(accessed 14 March 2021).

14. Comprehensive and Enhanced Partnership Agreement Between the European Union and the European Atomic Energy Community and Their Member States, of the One Part, and the Republic of Armenia, of the Other Part, 2017. URL: https:// www.consilium.europa.eu/en/documentspublications/treaties-agreements/agreement/
?id=2017024\&DocLanguage $=$ en $\quad$ (accessed 11 February 2021).

15. Democracy Index 2019. Economist Intelligence Unit, 2020. URL: https://www.eiu.com/ topic/democracy-index/ (accessed 4 March 2021).

16. European Parliament Recommendation of 4 July 2018 to the Council, the Commission and the Vice-President of the Commission. High Representative of the Union for Foreign Affairs and Security Policy on the Negotiations on the EU-Azerbaijan Comprehensive Agreement, 2018. URL: https:// www.europarl.europa.eu/doceo/document/TA-8-20180294_EN.html (accessed 4 March 2021).

17. European Union, Trade in Goods with Azerbaijan, 2021. URL: https://webgate.ec.europa.eu/ isdb_results/factsheets/country/details_azerbaijan_ en.pdf(accessed 14 April 2021).

18. Facts and Figures About EU-Azerbaijan Relations, 2020. URL: https://ec.europa.eu/ neighbourhood-enlargement/sites/near/files/ eap_factsheet_azerbaijan.pdf(accessed 3 April 2021).

19. Georgias Implementation of 20 Eastern Partnership Deliverables for 2020, 2020. URL: http:/ /gip.ge/georgias-implementation-of-20-easternpartnership-deliverables-for-2020/ (accessed 3 April 2021).

20. German T.C. Corridor of Power: The Caucasus and Energy Security. Caucasian Review of International Affairs, 2008, no. 2, pp. 64-65.

21. Implementation of the European Neighbourhood Policy in Armenia. Progress in 2014 and Recommendations for Actions: Joint Communication to the European Parliament, the Council, the European Economic and Social Committee and the Committee of the Regions. EC Doc. SWD (2015) 63 Final, Brussels, 2015. URL: https:// eeas.europa.eu/archives/docs/enp/pdf/2015/armeniaenp-report-2015_en.pdf(accessed 03 April 2021).

22. Joint Declaration of the Eastern Partnership Summit, 2017. URL: https://data.consilium.europa.eu/ doc/document/ST-14821-2017-INIT/en/pdf(accessed 12 April 2021).

23. Ministry of Finance, Georgia. State Budget, 2020. URL: https://mof.ge/5261 (accessed 12 April 2021).

24. Newsletter of the EU4Youth Programme, 2020. URL: https:/www.euneighbours.eu/sites/default/files/ publications/2020-12/EU4Youth_Newsletter_ December_2020.pdf(accessed 3 April 2021).

25. Regional Development Program of Georgia for 2018-2021 Years. Ministry of Regional Development and Infrastructure of Georgia, 2021. URL: http:// extwprlegs1.fao.org/docs/pdf/geo185566ENG.pdf5261 (accessed 7 April 2021). 


\section{МЕЖДУНАРОДНЫЕ ОТНОШЕНИЯ В ПРОШЛОМ И НАСТОЯЩЕМ}

\section{Information About the Authors}

Elena F. Parubochaya, Candidate of Sciences (History), Associate Professor, Department of International Relations, Political Science and Area Studies, Volgograd State University, Prosp. Universitetsky, 100, 400062 Volgograd, Russian Federation, parubochaya@volsu.ru, https://orcid.org/0000-0002-2115-6595

Anna S. Prygunkova, Expert of the Center for Public Diplomacy, Volgograd State University, Prosp. Universitetsky, 100, 400062 Volgograd, Russian Federation, prygunckova@volsu.ru, https://orcid.org/0000-0002-4185-5780

\section{Информация об авторах}

Елена Федоровна Парубочая, кандидат исторических наук, доцент кафедры международных отношений, политологии и регионоведения, Волгоградский государственный университет, просп. Университетский, 100, 400062 г. Волгоград, Российская Федерация, parubochaya@volsu.ru, https://orcid.org/0000-0002-2115-6595

Анна Сергеевна Прыгункова, эксперт Центра общественной дипломатии, Волгоградский государственный университет, просп. Университетский, 100, 400062 г. Волгоград, Российская Федерация, prygunckova@volsu.ru, https://orcid.org/0000-0002-4185-5780 